\title{
Pattern of EEG Change in Infants with West Syndrome: A Retrospective Study
}

Kanij Fatema ${ }^{1 *}$, Md Mizanur Rahman ${ }^{2}$, Shaheen Akhter ${ }^{3}$, Tania Saad ${ }^{4}$, Naznin Akter $^{5}$ and Suraiya Begum ${ }^{6}$

${ }^{1}$ FCPS (Pediatrics), FCPS (Pediatric Neurology and Development), Department of Pediatric Neurology, Bangabandhu Sheikh Mujib Medical University (BSMMU), Dhaka, Bangladesh

${ }^{2}$ FCPS (Pediatrics), Department of Pediatric Neurology, Bangabandhu Sheikh Mujib Medical University (BSMMU), Dhaka, Bangladesh

${ }^{3} \mathrm{MD}$ (Pediatrics), Institute of Pediatric Neurodisorder and Autism, BSMMU, Dhaka, Bangladesh

${ }^{4}$ FCPS (Pediatrics), BSMMU, Dhaka, Bangladesh

${ }^{5}$ FCPS (Pediatrics), FCPS (Pediatric Neurology and Development), Department of Pediatrics, Dhaka Medical College Hospital, Dhaka, Bangladesh

${ }^{6}$ FCPS (Pediatrics), Department of Pediatrics, BSMMU, Dhaka, Bangladesh

*Corresponding author: Fatema K, FCPS (Pediatrics), FCPS (Pediatric Neurology and Development), Department of Pediatric Neurology, Bangabandhu Sheikh Mujib Medical University (BSMMU), Dhaka, Bangladesh, Tel: +8801713097751; E-mail: mailmonami@gmail.com

Received date: July 22, 2018; Accepted date: July 31, 2018; Published date: August 08, 2018

Copyright: $\odot 2018$ Fatema K, et al. This is an open-access article distributed under the terms of the Creative Commons Attribution License, which permits unrestricted use, distribution, and reproduction in any medium, provided the original author and source are credited.

\begin{abstract}
West syndrome (WS) is a severe form of epilepsy of early infancy. Its diagnosis, evaluation, and management continue to pose many challenges to health care professionals and affected families.

Methodology: It is a retrospective review of patients of West syndrome who were followed up at least 6 months after diagnosis. We followed up 70 infants with West syndrome. EEG change of each follow up was recorded. For each individual child, we selected minimum three visits in the follow up period. Visit 1 was defined as the visit when the treatment for infantile spasms was started. Visit 2 at day 14 of first visit, Visit 3 at 6 month of first visit. Clinical data on file were used for analysis.

Results: Hypsarrhythmia initially was recorded in 20 of total number of 70 patients (28.6\%). Modified hypsarrhythmia was recorded in 40 infants $(57 \%)$, multifocal discharges were found in 7 patients $(10 \%)$. In third follow up at 6 month, first EEG showed a change of pattern with multifocal discharges in most of the cases $(52.9 \%)$ while EEG was normal in $24.3 \%$ of cases. $30 \%$ of our patients were completely free from clinical seizures at 6 months with $67 \%$ of them having normal EEG pattern and $29 \%$ with multifocal discharges.
\end{abstract}

Conclusion: Interictal EEG pattern changes with clinical course and with treatment.

Keywords: West syndrome; EEG; Hypsarrhythmia

\section{Introduction}

West syndrome (WS) is the most frequent epileptic encephalopathy in the first year of life [1]. It is considered as an epileptic syndrome that has 3 components, flexor/extensor type of epileptic spasms that usually occur in clusters, developmental stagnation or regression and electroencephalogram (EEG) evidence of an epileptic encephalopathy $[2,3]$. The peak age of onset is between 3 and 7 months; onset after 18 months is rare though onset upto 4 years of age has been reported [1].

The classic EEG signature of the epileptic encephalopathy in West syndrome was first described by Gibbs and Gibbs in 1952 who called it "hypsarrhythmia" [4]. However, hypsarrhythmia is not found in all cases, nor is it found throughout the clinical course of the condition $[5,6]$. A series of infants with epileptic spasm (ES) in clusters without hypsarrhythmia was published by Caraballo et al. [7].

Hypsarrhythmia usually disappears during a clinical attack of epileptic spasms. The interictal pattern is changed or replaced by another EEG pattern in course of disease [8]. Most pediatric neurologists believe that effective treatment for WS should produce both cessation of eplileptic spasm and resolution of hypsarrhythmia on EEG. In previous studies it has been proven that seizure relapse after initial treatment is dependent on EEG findings at control of ES [9].

In this study we present the electroclinical features and evolution of the EEG of patients with WS.

\section{Materials and Methods}

This is a retrospective study about the etiology and evolution of interictal EEG patterns of WS children referred to Department of Pediatric Neurology and Development of a tertiary care hospital conducted from January 2016 to February 2017. Seventy patients were selected, all having characteristic ES and developmental delay or regression at diagnosis. ES were identified as brief axial contractions occurring in clusters, observed by a trained pediatric neurologist and registered on EEG recording.

Age of onset, seizure semiology, birth history, developmental history, family history, and treatment history was recorded. Etiologies were analyzed. Detailed clinical and neurological examination was done. MRI was the preferred neuroimaging suggested for the patients 
Citation: Fatema K, Rahman MM, Akhter S, Saad T, Akter N, et al. (2018) Pattern of EEG Change in Infants with West Syndrome: A

Page 2 of 4

which was done in the first visit, however, CT scan was done in some patients due to financial constrain.

Treatment was given as per protocol of the department. First line drug was injection of ACTH in non-Tuberous sclerosis (TS) patients and Vigabatrin in TS patients. If there was failure of first line drug, then subsequently $\mathrm{Na}$ Valproate, topiramate, levetiracetam, oral steroid, vigabatrin (if previously not used) were given. Pyridoxin was given in selected cases. Minimum three visits were selected when EEG was done. Visit 1 was defined as the visit when the treatment for infantile spasms was started. Visit 2 at day 14 of first visit, visit 3 at 6 month of first visit. Mean time of follow up was 11 months, lowest follow up was 6 months and longest follow up was 3 years.

Hypsarrhythmia was characterized by an EEG with 0.5 to $3 \mathrm{~Hz}$ chaotic, asynchronous slow waves with voltages greater than $300 \mathrm{mV}$. Multifocal spikes and sharp and slow waves may also present. Intervals of attenuation can occur with and without clinical myoclonic activity or flexor spasms.

Modified hypsarrythmia was described by one of the following criteria: 1. Hypsarrhythmia with increased interhemispheric synchronization, 2. Asymmetrical hypsarrhythmia, 3. Hypsarrhythmia with a consistent focus of abnormal discharge, 4. Hypsarrhythmia with episodes of attenuation, and 5. Hypsarrhythmia comprising primarily high-voltage slow activity with little sharp-wave or spike activity [10].

\section{Results}

In this study total 70 children were included. The mean age of seizure onset was $7.92 \pm 2.52 \mathrm{SD}$ months. Most of the infants were male (58.5\%). The symptomatic (structural-metabolic) infants predominated (75.5\%) (Table 1).

Major predisposing risk factor event was perinatal asphyxia (38.5\%). Aetiological profile of patients is as given in Table 2.

EEG pattern of the patients: In first EEG 60 infants (85\%) showed hypsarrhythmia and 10 infants showed multifocal and other changes. In the subsequent EEG, number of patients with multifocal discharges increased. 23 (38\%) out of 60 of the hypsarrythmia cases evolved to multifocal discharges in the follow up EEG (last EEG) (Table 3).

\begin{tabular}{|l|l|l|}
\hline & N 70 & $\%$ \\
\hline Age of onset (mean) months & $5.65 \pm 2$ SD & \multicolumn{2}{|l|}{} \\
\hline $\begin{array}{l}\text { Sex: Male } \\
\text { Female }\end{array}$ & 41 & 58.5 \\
& 29 & 41 \\
\hline $\begin{array}{l}\text { Type of West Syndrome } \\
\text { Symptomatic (Structural-metabolic) } \\
\text { Cryptogenic (unknown) }\end{array}$ & 53 & 75.7 \\
\hline
\end{tabular}

Table 1: Clinico-demographic profile of the infants with West Syndrome.

\begin{tabular}{|l|l|l|}
\hline & N 70 & \% \\
\hline Prenatal & & \\
\hline Tuberous sclerosis & 2 & 2.85 \\
\hline Lissencephaly & 1 & 1.4 \\
\hline Corpus Callosal Agenesis & 3 & 4.2 \\
\hline TORCH & 5 & 7 \\
\hline Perinatal & 27 & 38.5 \\
\hline Perinatal Asphyxia & 6 & 8.57 \\
\hline Low birth weight/IUGR & 3 & 4.2 \\
\hline Neonatal Sepsis & 2 & 2.85 \\
\hline Postnatal & 4 & 5.71 \\
\hline Meningitis/Encephalitis & 17 & 24 \\
\hline Others & 27 & \\
\hline Cryptogenic & & \\
\hline
\end{tabular}

Table 2: Aetiological profile of patients with West Syndrome.

\begin{tabular}{|l|l|l|l|l|l|l|}
\hline \multirow{2}{*}{ Type of EEG } & \multicolumn{2}{l}{$1^{\text {st }}$ EEG } & \multicolumn{2}{l|}{$\mathbf{2}^{\text {nd }}$ EEG } & \multicolumn{2}{l|}{$\mathbf{3}^{\text {rd }}$ EEG } \\
\cline { 2 - 8 } & Symptomatic $\mathrm{n}(\%)$ & Cryptogenic & Symptomatic & Cryptogenic & Symptomatic & Cryptogenic \\
\hline Hypsarrhythmia & 17 & 3 & 10 & 2 & 3 & 1 \\
\hline Modified Hypsarrhythmia & 31 & 9 & 21 & 7 & 7 & 27 \\
\hline Multifocal discharge & 4 & 3 & 9 & 4 & 3 & 10 \\
\hline Others & 1 & 2 & 2 & 3 & 6 & - \\
\hline Normal & - & - & 11 & 6 & 4 & 4 \\
\hline
\end{tabular}

Table 3: EEG pattern in of patients in 3 visits.

Neuroimaging features: Neuroimaging was abnormal in 49 cases (70\%). Most common neuroimaging found in CT scan and MRI was cerebral atrophy (17 patients, $24 \%$ ). Calcification was due to tuberous sclerosis in 2 patients, Cytomegalovirus infection in 4 patients and hypoxic ischemic encephalopathy in 1 patient. Data from neuroimaging studies is associated with first EEG in Table 4. 


\begin{tabular}{|c|c|c|c|c|c|c|c|}
\hline & $\begin{array}{l}\text { Multicystic } \\
\text { enchephalom- } \\
\text { alacia } n-13\end{array}$ & $\begin{array}{l}\text { Normal } \\
\mathrm{n}-21\end{array}$ & $\begin{array}{l}\text { Cerebral } \\
\text { atrophy } n-17\end{array}$ & $\begin{array}{l}\text { Periventricular } \\
\text { leukomalacia n- } 5\end{array}$ & Calcification $n-7$ & $\begin{array}{l}\text { Developmental } \\
\text { malformation n-4 }\end{array}$ & $\begin{array}{l}\text { Others } \\
\mathrm{n}-3\end{array}$ \\
\hline Hypsarrhythmia n- 20 & 3 & 8 & 5 & 2 & 2 & - & - \\
\hline Modified Hypsarrhythmia n- 40 & 9 & 12 & 10 & 2 & 4 & 2 & 1 \\
\hline Multifocal discharge $n-7$ & 1 & 1 & 1 & - & 1 & 2 & 1 \\
\hline Others $n-3$ & - & & 1 & 1 & & & 1 \\
\hline
\end{tabular}

Table 4: $1^{\text {st }}$ EEG pattern and neuroimaging of the patients.

\begin{tabular}{|l|l|l|l|l|l|}
\hline & $\begin{array}{l}\text { Epileptic } \\
\text { spasm } \\
\text { persistin } \\
\mathbf{g} \text { n-13 }\end{array}$ & $\begin{array}{l}\text { No } \\
\text { seizur } \\
\text { e n-21 }\end{array}$ & $\begin{array}{l}\text { Generalize } \\
\text { d seizure n- } \\
\mathbf{1 7}\end{array}$ & $\begin{array}{l}\text { Focal } \\
\text { seizur } \\
\text { e n-16 }\end{array}$ & $\begin{array}{l}\text { LGS } \\
\text { n-3 }\end{array}$ \\
\hline $\begin{array}{l}\text { Classical } \\
\text { Hypsarrhythmia: } 4\end{array}$ & 2 & - & 1 & 1 & \\
\hline $\begin{array}{l}\text { Modified } \\
\text { Hypsarrhythmia: } 9\end{array}$ & 2 & 1 & 2 & 4 & - \\
\hline Multifocal discharge: 37 & 9 & 6 & 10 & 10 & 2 \\
\hline Others 3 & - & - & 1 & 1 & 1 \\
\hline Normal 17 & - & 14 & 3 & - & - \\
\hline
\end{tabular}

Table 5: Last EEG pattern and seizure pattern in last visit.

Normalization of EEG has been found in 17 patients in last EEG (in $3^{\text {rd }}$ visit), out of which $14(82 \%)$ patients were free from any seizure and rest 3 had generalized seizure (Table 5).

\section{Discussion}

Historically WS refers to classic triad of spasms, hypsarrhythmia and psychomotor arrest or regression [11]. EEG is an integral part of diagnosis of West Syndrome. This retrospective study was, therefore, conducted with the target of exploring the clinical pattern and spectrum of EEG changes in WS in a resource-constrained setting of a developing country.

The typical age of onset of WS is between 3 and 12 months of age (peak at 5 months) and males predominate (60\%-70\%) [12]. Our study also shows the mean age of onset being 5.65 months with slight male preponderance (58.5\% vs. $41 \%)$.

Aetiologically, WS is classified, in order of prevalence, as symptomatic (about $80 \%$ of all) due to discernible organic insults, and cryptogenic or idiopathic. Symptomatic WS is by far the most common [12]. The proportion of symptomatic cases was also higher in our study (75.7\%). This is comparable to the findings of Kaushik et al. in a study done in Northern India (82\%) [13] and of Matta et al. from Brazil (72.6\%) [14] while in the United Kingdom Infantile Spasms Study (UKISS) symptomatic cases were 61\% [15].

Among the several pre-, peri- and postnatal insults responsible for WS, adverse perinatal events are the most important causes [16,17]. In our study we found the perinatal causes being more common than the prenatal ones and among them perinatal asphyxia was the most prevalent (38.5\%). This finding goes in accordance with other studies

from developing countries $[13,18]$. On the contrary, prenatal causes like cortical malformations, neurocutaneous syndrome and geneticmetabolic disorders contribute the majority in western countries $[15,19]$. The commonest prenatal cause in our study was TORCH infections (7\%). These two findings are indicative of lack of awareness and poorer maternal and neonatal health services in developing countries as compared to that of developed countries. Two of our patients who had calcification had tuberous sclerosis complex in the $\mathrm{CT}$ scan and were treated with vigabatrin as first line drug.

In a child with suspected WS, an EEG is needed to confirm the presence of hypsarrhythmia first. Given the state- dependence of hypsarrhythmia, an extended EEG recording that captures at least one full sleep-wake cycle should be performed in all cases [1]. However, hypsarrhythmia is not found in all cases, nor is it found throughout the clinical course of the condition [20]. Symmetrical and other patterns of modified or atypical hypsarrhythmia occur in a third of cases. Their presence depends on the stage of WS at which the EEG is performed [12].

There are few studies reporting on the evolution of interictal patterns in WS. With the view of observing the evolution of EEG patterns we took into accounts at least 3 EEG recordings for each patient: at the onset of treatment, 2 weeks after and 6 months after the first EEG. On the first EEG we found modified hypsarrhythmia in most of the cases (57\%) followed by hypsarrhythmia $(28.6 \%)$ and multifocal discharges (10\%). EEG done 2 weeks after the onset of treatment revealed that EEG became normal in $15.7 \%$ of cases while modified hypsarrhythmia was still present in $40 \%$ of cases followed by multifocal discharges (18.6\%) and hypsarrhythmia (17\%). On the third follow up done 6 months after the first EEG showed a change of pattern with multifocal discharges in most of the cases $(52.9 \%)$ while EEG was normal in $24.3 \%$ of cases. Modified hypsarrhythmia and hypsarrhythmia were still present in $12.9 \%$ and $5.7 \%$ of cases respectively.

As hypsarrhythmia is an age dependent EEG abnormality, it is always replaced by another pattern in the EEG done after few months or years while EEG may evolve to normality after disappearance of hypsarrhythmia in idiopathic WS [21]. The classic studies of Gibbs et al. revealed that $75 \%$ of children with WS remained with focal discharges after the disappearance of hypsarrhythmia [4]. Study done by Mata et al. also found multifocal discharges evolving from hypsarrhythmia on follow up in most of the cases [21]. These findings are consistent with that of ours.

Neuroimaging was done in all cases. While comparing the baseline EEG pattern with neuroimaging it was derived that imaging study was normal in $30 \%$ of modified hypsarrhythmia and $40 \%$ of 
hypsarrhythmia group. Multifocal encephalomalacic changes were found in $22.5 \%$ of modified and $15 \%$ of hypsarrhythmia groups. Other pattern of imaging findings included cortical atrophy (in $24.3 \%$ of all cases), periventricular leukomalacia (7.14\%), calcifications $(10 \%)$ and developmental malformations (5.7\%). Mata et al. also found detectable brain lesions on neuroimaging in $75 \%$ of cases with half of them having cerebral atrophy or multicystic encephalomalacia [4]. These findings correspond exactly with that of ours.

Cessation of spasm is the most important outcome measure in the early phase of the disease, as it is generally believed that the earlier the control of spasm, the better the developmental outcome can be [22]. However, about $50 \%$ of children will develop other seizure types [1]. While correlating the last EEG pattern of the patients with seizure, we found that $30 \%$ of our patients were completely free from clinical seizures at 6 months with $67 \%$ of them having normal EEG pattern and $29 \%$ with multifocal discharges. Eighteen percent of patients continued to have epileptic spasms while $24 \%$ developed generalized seizure and $22 \%$ focal seizure. Three patients (4\%) turned into Lennox Gastaut Syndrome.

Regardless of treatment, it appears that clinical spasm and hypsarrhythmia disappear in $50 \%$ of children by 2 years of age [11]. The relatively lower number of response rate in our study is better explained by the shorter follow up period of 6 months. Better correlation of EEG pattern with seizure can, therefore, be done by further long term follow up.

\section{Conclusion}

In conclusion our study revealed that symptomatic (now metabolicstructural) WS is still the most common form of WS in a recourse limited setting with perinatal asphyxia being the main cause. Most common form of EEG is modified hypasrrhythmia on diagnosis while in course of time a significant number turns into multifocal discharges. While normalization of EEG in last visit was associated with freedom of seizure.

\section{References}

1. Hrachovy RA, Frost JD (2008) Severe encephalopathic epilepsy in infants: infantile spasms (West syndrome). In. Pediatric Epilepsy: Diagnosis and Therapy. Edited by Pellock JM, Boorgeois BF, Dodson WE, Nordi DR Jr, Sankar R. New York, NY: Demos Medical Publishing 249: 68.

2. Pellock JM, Hrachovy RA, Shinnar S, Baram TZ, Bettis D, et al. (2010) Infantile spasms: a U.S. consensus report. Epilepsia 51: 2175-2189.

3. Mackay MT, Weiss SK, Adams-Webber T, Ashwal S, Stephens D, et al. (2004) Practice parameter: medical treatment of infantile spasms: report of the American Academy of Neurology and the Child Neurology Society. Neurology 62: 1668-1681.

4. Gibbs FA, Gibbs EL (1952) Atlas of Electroencephalography, 2nd ed.Addison-Wesley Press, Inc, Cambridge, Massachusetts. 222-224.
5. Gobbi G, Bruno L, Pini A, Rossi PG, Tassinari CA (1987) Periodic spasms: an unclassified type of epileptic seizure in childhood. Dev Med Child Neurol 29: 766-775.

6. Bednarek N, Motte J, Soufflet C, Plouin P, Dulac O (1998) Evidence of late-onset infantile spasms. Epilepsia 39: 55-60.

7. Caraballo RH, Fejerman N, Bernardina BD, Ruggieri V, Cersósimo R, et al. (2003) Epileptic spasms in clusters without hypsarrhythmia in infancy. Epileptic Disord 5: 109-113.

8. Lux AL, Osborne JP (2004) A proposal for case definitions and outcome measures in studies of infantile spasms and West syndrome: consensus statement of the West Delphi group. Epilepsia 45: 1416-1428.

9. Yamada K, Toribe Y, Kimizu T, Kimura S, Ikeda T, et al. (2014) Predictive value of EEG findings at control of epileptic spasms for seizure relapse in patients with West syndrome. Seizure 23: 703-707.

10. Hrachovy RA, Frost JD Jr, Kellaway P (1984) Hypsarrhythmia: variation on the theme. Epilepsia 25:317-325.

11. Singhal NS, Harini C, Sullivan J (2018) Epileptic Spasms and Myoclonic Seizures. In: Swaiman KF, Ashwal S, Ferriero DM, editors. Swaiman's Pediatric Neurology. 6th edition. London: Elsevier.

12. Panayiotopoulos CP (2011) A Clinical Guide to Epileptic Syndromes and their Treatment. 2nd edition. London: Springer.

13. Kaushik JS, Patra B, Sharma S, Yadav D, Aneja S (2013) Clinical spectrum and treatment outcome of West Syndrome in children from Northern India. Seizure 22: 617-621.

14. Matta AP, Chiacchio SV, Leyser M (2007) Possible etiologies of West Syndrome: evaluation of 95 patients. Arg Neuropsiquiatr 65: 659-662.

15. Osborne JP, Lux AL, Edwards SW, Hancock E, Johnson AL, et al. (2010) The underlying etiologies of infantile spasms (West Syndrome): Information from the United Kingdom Infantile Spasms Study (UKISS) on contemporary causes and their classification. Epilepsia 51: 2168-2174.

16. Kalra V, Gulati S, Pandey RM, Menon S (2002) West Syndrome and other infantile epileptic encephalopathies- Indian hospital experience. Brain Dev 24: 130-139.

17. Singhi P, Ray M (2005) Profile of West Syndrome in North Indian children. Brain Dev 27: 135-140.

18. Gulati S, Jain P, Kannan L, Sehgal R, Chakrabarty B (2015) The Clinical Characteristics and Treatment Response in Children with West Syndrome in a Developing Country: A Retrospective Case Record Analysis. J Child Neurol 30: 1440-1447.

19. Cowan LD, Hudson LS (1991) The epidemiology and natural history of infantile spasms. J Child Neurol 6: 355-364.

20. Caraballo RH, Ruggieri V, Gonzalez G, Cersósimo R, Gamboni B, et al. (2011) Infantile Spasms without hypsarrhythmia: A study of 16 cases. Seizure 20: 197-202.

21. Mata NS, Liberalesso PBN, Marques JM, Zeigelboim BS, Garzon E (2015) West Syndrome: etiology and evolution of the inter-ictal EEG pattern in a cohort of 24 patients. J epilepsy clin neurophysiol 21: 15-18.

22. Lagae L, Verhelst H, Ceulemans B, De Meirleir L, Nassogne MC, et al. (2010) Treatment and long term outcome in West Syndrome: The clinical reality. A muilticentre follow up study. Seizure 19: 159-164. 